\title{
Fracture Resistance of Roots Restored with Four Different Fiber-Reinforced Composite Posts
}

\author{
Necdet Adanir Buglem Ureyen Kaya Ayse Diljin Kececi \\ Department of Endodontics, Faculty of Dentistry, Suleyman Demirel University, Isparta, Turkey
}

\section{Key Words}

Fiber post - Vertical root fracture $\cdot$ Resin cement .

Fracture resistance $\cdot$ Root canal therapy

\begin{abstract}
Objective: The aim of this study was to compare the resistance to vertical root fracture of root-filled teeth restored with four different fiber-reinforced composite (FRC) post systems and two types of dual-cured resin luting agents. Materials and Methods: Ninety extracted human maxillary central incisors were selected and decoronated to obtain a standardized root length of $14 \mathrm{~mm}$. After root canal obturation, post spaces were prepared to a depth of $10 \mathrm{~mm}$ with a No. 3 post drill. The specimens $(n=80)$ were divided into two groups $(n=40)$ according to the resin luting agents used: group 1, Variolink II + ExciTE DSC; group 2, RelyX Unicem. These groups were subdivided into four subgroups $(n=10)$ and restored with one of the following post systems: (a) DT Light, (b) DT Light SL, (c) FRC Postec and (d) Everstick, while the remaining 10 teeth served as controls. The roots were subjected to axial compressive loading using a $2.2-\mathrm{mm}$-diameter metal sphere in a universal testing machine $(0.5 \mathrm{~mm} /$ min). A factorial experiment with a single control group (analysis of variance) was used to test the resistance of the specimens. Results: Groups 2a (DT Light + RelyX Unicem;
\end{abstract}

398.5 N) and 1b (DT Light SL + Variolink II + ExciTE DSC; 431.1 $\mathrm{N})$ had significantly higher resistance to fracture than the control group ( $334.1 \mathrm{~N} ; \mathrm{p}<0.05$ ). DT Light SL and FRC Postec Plus were more resistant to fracture when Variolink II was used as the luting cement. DT Light and Everstick had higher fracture resistance when they were luted with RelyX Unicem $(p<0.05)$. Conclusion: The results of this study indicate that the use of quartz fiber posts (DT Light and DT Light SL) with an adhesive luting cement in root-filled teeth may reinforce the root to some extent.

(c) 2015 S. Karger AG, Basel

\section{Introduction}

When the remaining tooth structure cannot provide adequate support and retention for restoration, endodontically treated teeth are usually restored with posts $[1,2]$. Restoring these teeth using materials with a similar elastic modulus to dentine appears advantageous due to the reduced risk of root fracture [3]. The fracture resistance of endodontically treated teeth has been reported to be principally dependent on the amount of remaining tooth structure and adhesive surface, the quality of adhesion, and the type of post because posts increase the fracture resistance of the root, especially in the absence of a

\begin{tabular}{ll}
\hline KARGER 125:s & $\begin{array}{l}\text { () 2015 S. Karger AG, Basel } \\
1011-7571 / 15 / 0246-0538 \$ 39.50 / 0 \quad \text { Karger }\end{array}$ \\
$\begin{array}{l}\text { E-Mail karger@karger.com } \\
\text { www.karger.com/mpp }\end{array}$ & $\begin{array}{l}\text { This is an Open Access article licensed under the terms of the } \\
\text { Creative Commons Attribution-NonCommercial 3.0 Un- } \\
\text { ported license (CC BY-NC) (www.karger.com/OA-license), } \\
\text { applicable to the online version of the article only. Distribu- } \\
\text { tion permitted for non-commercial purposes only. }\end{array}$
\end{tabular}

Dr. Bulem Ureyen Kaya

Department of Endodontics, Faculty of Dentistry

Suleyman Demirel University, Dogu Kampusu

TR-32260 Isparta (Turkey)

E-Mail bureyen@hotmail.com 
full crown [4]. However, both cast and prefabricated posts made of metal alloys present some drawbacks, such as causing irreparable root fractures, biocompatibility problems, compromising esthetics, difficulty in removing metal posts, and the risk of corrosion or allergic reaction [5]. On the other hand, the elastic modulus of glass fiber posts is reported to be similar to that of dentine, and these posts have a homogeneous force distribution that minimizes catastrophic root fracture [3].

Clinicians have tried to support the remaining tooth structure using various adhesive dental materials that may offer a valuable opportunity to strengthen the endodontically treated teeth. These materials include bonded sealers or fiber-reinforced composite (FRC) posts with adhesive luting cement in the root canal system. In recent years different luting agents, including adhesive systems, have been recommended for bonding fiber-reinforced posts to root canal dentine. These bonding agents are mainly divided into total-etch and self-etching adhesive systems [6]. Self-adhesive resin cement can be applied in a single clinical step and, although studies have reported limited infiltration of resin cement into dental tissue, its main adhesive property is attributed to a chemical reaction between phosphate methacrylates and hydroxyapatite [7].

Although the effects of different root canal sealers on vertical root fracture (VRF) are well documented [8], there is no study on the effect of the FRC post system and resin cement on VRF. Therefore, the aim of this study was to compare the resistance to VRF of root-filled teeth restored with four different FRC post systems and two types of dual-cured resin luting agents.

The null hypotheses of this study were: (a) FRC posts do not result in any increase in the fracture resistance of endodontically treated teeth compared to root-filled teeth without posts, and (b) there is no statistically significant difference between the resin cements used in this study.

\section{Materials and Methods}

\section{Specimen Preparation}

Ninety maxillary central incisor teeth with straight root canals, extracted for periodontal reasons, were selected for this study. All specimens were fully developed apices and had no cracks, caries or fractures. The buccopalatal and mesiodistal dimensions of the teeth were measured at the highest bulge with a digital caliper (Digimatic Calipers, Mitsutoyo, Tokyo, Japan). The teeth were carefully cleaned with a scaler to remove any debris, placed in $2.5 \%$ sodium hypochlorite $(\mathrm{NaOCl})$ for $2 \mathrm{~h}$ for surface disinfection and then stored in $0.1 \%$ sodium azide solution until use.

Fracture Resistance of Fiber-Reinforced Posts

\section{Endodontic Treatment}

The crowns of the teeth were removed with a $0.15-\mathrm{mm}$ diamond wafering blade (Buehler Ltd., Lake Bluff, Ill., USA) under water cooling to give uniform $14-\mathrm{mm}$ apical sections of root. The root canals were prepared manually using a step-back technique to an apical size of ISO 40. After changing each instrument, the root canals were irrigated with $2 \mathrm{ml}$ of $2.5 \% \mathrm{NaOCl}$ solution. The canals were dried with absorbent paper points (Dentsply Maillefer, Tulsa, Okla., USA) and filled with gutta-percha and AH Plus sealer (Dentsply Caulk, Milford, Del., USA) using the cold lateral compaction technique.

\section{Post Space Preparation}

The post space preparation of all roots was initiated after 7 days to allow the sealer to set. Post spaces were prepared to a depth of $10 \mathrm{~mm}$ with a special preparation drill (No. 3 FRC Postec Plus drill; Ivoclar Vivadent, Schaan, Liechtenstein) which had a 1.0$\mathrm{mm}$ diameter apically and a 0.02 taper. After post space preparation, the canals were irrigated using sterile water and dried with paper points (Dentsply Maillefer). The presence of any residual gutta-percha on the walls of the post space was evaluated by radiographic imaging.

\section{Post Cementation}

The specimens were assigned to two groups (each $n=40$ ) according to the resin luting agents used: group 1, Variolink II + ExciTE DSC; group 2, RelyX Unicem. These groups were subdivided into four subgroups $(n=10)$ and reconstructed with one of the four types of posts: (a) DT Light, (b) DT Light SL, (c) FRC Postec and (d) Everstick. The remaining 10 teeth served as controls. Thus, the groups investigated in this study are listed below.

Group 1a: DT Light posts (Vereinigte Dentalwerke, Munich, Germany) luted with ExciTE DSC and Variolink II (both from Ivoclar Vivadent).

Group 1b: Quartz fiber posts (DT Light SL posts; Vereinigte Dentalwerke) were luted using an ExciTE DSC and Variolink II combination.

Group 1c: Glass fiber posts (FRC Postec Plus posts; Ivoclar Vivadent) were luted with ExciTE DSC and Variolink II.

Group 1d: Individually formed glass fiber posts (Everstick; StickTech Ltd., Turku, Finland) were luted using ExciTE DSC and Variolink II, according to the manufacturer's instructions.

Group 2a: DT Light posts luted with self-adhesive resin cement (RelyX Unicem; 3M ESPE, St. Paul, Minn., USA).

Group 2b: DT Light SL posts were luted with RelyX Unicem.

Group 2c: FRC Postec Plus posts were luted with RelyX Unicem.

Group 2d: Everstick was luted with RelyX Unicem.

Control: No post space preparation and reconstruction.

After the posts were checked and confirmed for length and fit, the post surfaces were cleaned with alcohol, as recommended by the manufacturer. Variolink II was used after rinsing the root canal spaces with distilled water and etching with $35 \%$ phosphoric acid (Ultra-Etch; Ultradent, South Jordan, Utah., USA) for $15 \mathrm{~s}$. The ExciTE DSC single-dose adhesive system was used via a microbrush coated with chemical initiators to intra-radicular dentine and scrubbed for $10 \mathrm{~s}$. Excess adhesive was removed with paper points and gently air dried. The resin was polymerized using a halogen light unit Optilux 501 (Kerr Dental, Orange, Calif., USA) with an intensity of $800 \mathrm{~mW} / \mathrm{cm}^{2}$ for $20 \mathrm{~s}$ with the tip of 


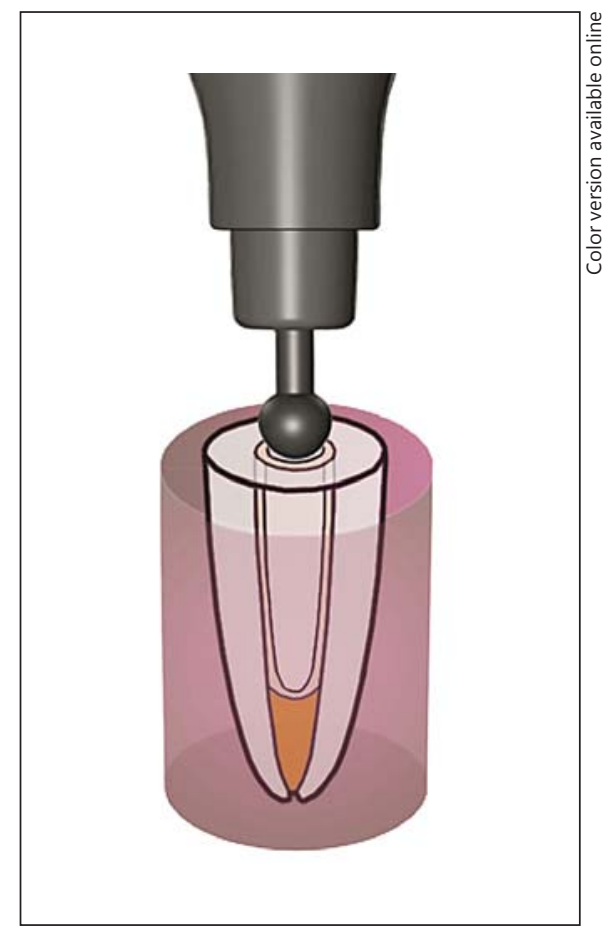

Fig. 1. Schematic representation of the setup for the assessment of fracture resistance.

the light unit directly in contact with the canal orifice. The surfaces of FRC Postec Plus posts were silanized with Monobond-S (Ivoclar-Vivadent) with a disposable microbrush for $60 \mathrm{~s}$. All posts in group 1 were luted with dual-polymerized resin cement (Variolink II) after applying the dual-curing adhesive system (ExciTE DSC single dose) according to the manufacturer's instructions.

Self-adhesive dual-polymerized cement (RelyX Unicem Aplicap) was used in the group 2 subgroups as a luting agent. RelyX Unicem was prepared according to the manufacturer's instructions and applied directly to the root canal space. The post was also covered with the cement. Polymerization was performed as previously described.

The root surfaces were covered with a thin layer of silicone impression material (Speedex; Colten AG, Altstätten, Switzerland) to simulate the function of the periodontal ligament and embedded in an autopolymerizing acrylic resin (Meliodent; Heraeus Kulzer, Hanau, Germany) up to $2 \mathrm{~mm}$ below the enamelcementum junction to simulate the alveolar bone. Approximately $1.00 \pm 0.05-\mathrm{mm}$-thick slices of the coronal portion of each root were sectioned perpendicular to the long axis with a low-speed saw to create a smooth surface. The roots were subjected to axial compressive loading using a 2.2-mm-diameter metal sphere in a universal testing machine (Testometric, Rochdale, UK) at 0.5 $\mathrm{mm} / \mathrm{min}$, and the fracture load was recorded (in newtons, $\mathrm{N}$; fig. 1). The axial compressive load was defined as any sudden load drop during compression and was recorded for each specimen $(\mathrm{N})$.
Table 1. Fracture resistance $(\mathrm{N})$

\begin{tabular}{lll}
\hline Groups & Mean \pm SD & Range \\
\hline $\begin{array}{l}\text { Group 1 } \\
\text { Excite DSC/Variolink II }\end{array}$ & \\
$\quad$ (a) DT Light & $341.3 \pm 23.8$ & $290.8-366.9$ \\
$\quad$ (b) DT Light SL & $431.1 \pm 57.8^{\mathrm{a}}$ & $301.7-530.1$ \\
$\quad$ (c) FRC Postec Plus & $377.0 \pm 49.2$ & $324.4-454.9$ \\
$\quad$ (d) Everstick & $305.8 \pm 52.0$ & $242.7-386.4$ \\
\hline Group 2 & & \\
RelyX Unicem & & \\
$\quad$ (a) DT Light & $398.5 \pm 56.3^{\mathrm{b}}$ & $306.4-490.7$ \\
$\quad$ (b) DT Light SL & $358.5 \pm 52.6$ & $282.2-440.4$ \\
(c) FRC Postec Plus & $276.9 \pm 61.4$ & $218.0-399.5$ \\
$\quad$ (d) Everstick & $358.4 \pm 58.7$ & $250.9-429.1$ \\
\hline Control group & $334.1 \pm 48.9$ & $260.9-414.2$ \\
\hline
\end{tabular}

Significant difference from the control group according to Dunnett's test: ${ }^{\mathrm{a} o} \mathrm{t}=-2.62 ;{ }^{\mathrm{bo}} \mathrm{t}=-3.94$.

\section{Statistical Analysis}

A factorial experiment with a single control group (analysis of variance) was used to test the resistance of the specimens to VRF. Dunnett's test was used to assess the differences between the experimental groups and the control group. The statistical significance among the mean fracture resistance of the experimental groups was determined with Tukey's HSD (honest significant difference) test. The confidence level was set to $95 \%$ in all tests.

\section{Results}

The mean and standard deviations, fracture resistance, and the range of the experimental and control groups are presented in table 1. A factorial experiment with a single control group showed that the interaction between luting cements and posts was significant $(\mathrm{F}=11.20 ; \mathrm{p}=0.00$; table 2). The difference between the experimental groups and the control group was also statistically significant $(\mathrm{F}=246.50 ; \mathrm{p}=0.00$; table 2$)$. Groups $1 \mathrm{~b}$ and $2 \mathrm{a}$ had significantly higher resistance to fracture values than the control group according to Dunnett's test $(t=-2.62$ and -3.94 , respectively). Tukey's HSD test indicated a significant difference among the experimental groups ( $\mathrm{p}<$ 0.05). DT Light SL and FRC Postec Plus were more resistant to fracture when Variolink II was used as the luting cement. DT Light and Everstick had higher fracture resistance when they were luted with RelyX Unicem ( $<<0.05$; table 3$)$. 
Table 2. Results of the factorial experiment with a single control group: (ANOVA) statistical analysis

\begin{tabular}{lrrrr}
\hline Source of variation & d.f. & Mean square & F & p value \\
\hline Control group $\times$ experimental groups & 1 & 745,528 & 246.5 & 0.000 \\
Luting cements & 1 & 4,937 & 1.63 & 0.186 \\
Post types & 3 & 20,756 & 6.86 & 0.000 \\
Luting cements $\times$ post types & 3 & 33,888 & 11.20 & 0.000 \\
Error & 81 & 3,025 & & \\
\hline
\end{tabular}

\begin{tabular}{llc}
\hline Luting cement & Post type & Fracture resistances, N \\
\hline ExciTE DSC + Variolink II & DT Light & $341.26 \pm 23.82^{\mathrm{b}, \mathrm{c}}$ \\
& DT Light SL & $431.1 \pm 57.8^{\mathrm{a}}$ \\
& FRC Postec Plus & $377.0 \pm 49.2^{\mathrm{a}, \mathrm{b}}$ \\
& Everstick & $305.8 \pm 52.0^{\mathrm{c}}$ \\
RelyX Unicem & DT Light & $398.5 \pm 56.3^{1}$ \\
& DT Light SL & $358.5 \pm 52.6^{1}$ \\
& FRC Postec Plus & $276.9 \pm 61.4^{2}$ \\
& Everstick & $358.4 \pm 58.7^{1}$ \\
\hline \multirow{2}{*}{ Post type } & Luting cement & Fracture resistances, N \\
\hline \multirow{2}{*}{ DT Light } & ExciTE DSC + Variolink II & $341.26 \pm 23.82^{\mathrm{b}}$ \\
& RelyX Unicem & $398.5 \pm 56.3^{\mathrm{a}}$ \\
DT Light SL & ExciTE DSC + Variolink II & $431.1 \pm 57.8^{1}$ \\
& RelyX Unicem & $358.5 \pm 52.6^{2}$ \\
FRC Postec Plus & ExciTE DSC + Variolink II & $377.0 \pm 49.2^{\alpha}$ \\
& RelyX Unicem & $276.9 \pm 61.4^{\beta}$ \\
Everstick & ExciTE DSC + Variolink II & $305.8 \pm 52.0^{\mathrm{ii}}$ \\
& RelyX Unicem & $358.4 \pm 58.7^{\mathrm{i}}$ \\
\hline
\end{tabular}

Values are mean \pm SD. Groups followed by the same symbol within the column are not statistically significant $(\mathrm{p}>0.05)$.

\section{Discussion}

With the exception of groups $2 \mathrm{a}$ and $1 \mathrm{~b}$, results from the groups in the present study revealed that the presence of a post was not significant to the vertical fracture strength, confirming that the primary purpose of a post is to retain a core or restoration and not to reinforce a root canal [9]. Some authors argue that there is no significant difference in largely compromised teeth between teeth restored with and without posts due to the use of an adhesive restorative design [9]. The first null hypothesis that FRC posts would not result in any increase in the fracture resistance of endodontically treated teeth compared to root-filling therapy alone (without posts) was partially accepted.

Perez-Gonzalez et al. [10] compared the strength of maxillary incisors restored with glass fiber posts without a crown, as in the present study. However, the mean failure load $(211.2 \mathrm{~N})$ was less than that obtained in the present study. This difference can be attributed to their use of a procedure where the specimens were tested under a tension load.

Independent of tensile or compressive stress, the greatest stress appears to occur in the cervical region [11], confirming our observations that fractures mostly occurred in the that region. The posts concentrated stress in the cervical region because of their flexibility. It is known that the ordinary chewing force in adults ranges from 7 to 15 $\mathrm{kg}$ [12], but that the maximum biting force is up to $90 \mathrm{~kg}$ [13]. In the present investigation, root-filled teeth with or without posts were able to resist the normal chewing force, but this was not as strong as the maximum biting force. Hayashi et al. [14] reported higher fracture strength 
values for the DT Light post ( $153 \mathrm{kgf}$ for $90^{\circ}$ vertical loading and $56 \mathrm{kgf}$ for $45^{\circ}$ oblique loading) compared to the values of the roots in the present study. The fracture resistance of the roots in our study was determined without core restoration that simulates the worst-case scenario, and this may have caused the lower fracture loads. The methods of fabrication of DT Light posts can provide an explanation for the significantly higher resistance to fracture. The type of resinous matrix and the fabrication process used to promote chemical bonding between fiber and resin may possibly be the most important factors influencing the fiber post strength [15].

In the present study, Everstick showed low fracture resistance in accordance with the findings of Le Bell-Rönnlöf et al. [16]. A post situated in the most central part of the tooth, where stresses are minimal, does not reinforce the root. It was reported that for mechanically optimum results the reinforcement has to be as far away from the neutral axis as possible, producing a structure that is similar to the intact tooth, which is hollow in the middle. In the present study, Everstick cemented with Variolink II or RelyX Unicem showed no statistical difference when compared to the control. However, the results of the Everstick luted with the Variolink II groups showed a statistically significant lower value than the silane-applied posts luted with Variolink II. This result was consistent with the findings of Cekic-Nagas et al. [17] that the conditioning of the post surface has positive effects on bond strength.

It was shown that the injection method used to carry the RelyX Unicem luting cement into the post space resulted in fewer air bubbles and voids in all specimens [18]. So, the marginal adaptation of the material of both the dental substrate and the fiber post was improved. A recent study demonstrated that fiber posts luted with 1-step self-etch dual-polymerized resin cements had significantly higher bond strengths [19]. Zicari et al. [20] found that the self-adhesive composite cement RelyX Unicem was as effective as the multistep composite cement. They reported higher fracture loads than those of the specimens luted with RelyX Unicem in the present study. This may be due to the orientation of the load.

DT Light SL posts luted with ExciTE DSC and Variolink II in the $35 \%$ phosphoric acid etching groups showed significantly higher vertical fracture strengths compared with the FRC Postec Plus/RelyX Unicem, Everstick/ExciTE DSC/Variolink II and the control groups. This may have resulted from the positive effects of silanization of the post and the dentine surface being conditioned with acid etching. This result is partially consistent with Sahinkesen et al. [21] who reported that Variolink II and silanization of the post combination achieved the highest bond strength values. However, other silane coupling agent groups (Postec Plus/RelyX Unicem) demonstrated the lowest mean bond strength values. This can be explained by the fact that silanization alone does not sufficiently increase the value of the bond strength unless a proper luting cement is used. However, in another silane group (FRC Postec Plus luted with ExciTE DSC/Variolink II) fracture resistance significantly increased. Therefore, the second null hypothesis of this study was rejected.

\section{Conclusions}

The results of this study indicate that the use of quartz fiber posts (DT Light and DT Light SL) with an adhesive luting cement in root-filled teeth may reinforce the root to some extent.

\section{References}

1 Morgano SM, Bowley JF, Thalib L, et al: A survey of contemporary philosophies and techniques of restoring endodontically treated teeth in Kuwait. Med Princ Pract 2001;10:1422.

$>2$ Ureyen Kaya B, Kececi AD, Guldas HE, et al: A retrospective radiographic study of coronal-periapical status and root canal filling quality in a selected adult Turkish population. Med Princ Pract 2013;22:334-339.

-3 Adanir N, Belli S: Stress analysis of a maxillary central incisor restored with different posts. Eur J Dent 2007;1:67-71.
4 Santana FR, Castro CG, Simamoto-Junior $\mathrm{PC}$, et al: Influence of post system and remaining coronal tooth tissue on biomechanical behaviour of root filled molar teeth. Int Endod J 2011;44:386-394.

5 Schwartz RS, Robbins JW: Post placement and restoration of endodontically treated teeth: a literature review. J Endod 2004;30: 289-301.

-6 Esclassan Noirrit E, Grégoire G, Cournot M: Morphological study of fiber-reinforced postbonding system-root dentin interface by evaluation of two bonding systems. J Dent 2008; 36:204-213.
7 Monticelli F, Osorio R, Mazzitelli C, et al: Limited decalcification/diffusion of self-adhesive cements into dentin. J Dent Res 2008; 87:974-979.

$>8$ Ersev H, Yilmaz B, Pehlivanoglu E, et al: Resistance to vertical root fracture of endodontically treated teeth with metaseal. J Endod 2012;38:653-656.

$\checkmark 9$ Valdivia AD, Raposo LH, Simamoto-Junior PC, et al: The effect of fiber post presence and restorative technique on the biomechanical behavior of endodontically treated maxillary incisors: an in vitro study. J Prosthet Dent 2012;108:147-157. 
10 Perez-Gonzalez A, Gonzalez-Lluch C, Sancho-Bru JL, et al: Experimental strength of restorations with fibre posts at different stages, with and without using a simulated ligament. J Oral Rehabil 2012;39:188-197.

11 Mattos CM, Las Casas EB, Dutra IG, et al: Numerical analysis of the biomechanical behaviour of a weakened root after adhesive reconstruction and post-core rehabilitation. J Dent 2012;40:423-432.

12 Anderson DJ: Measurement of stress in mastication. I. J Dent Res 1956;35:664-670.

13 Tortopidis D, Lyons MF, Baxendale RH, et al: The variability of bite force measurement between sessions, in different positions within the dental arch. J Oral Rehabil 1998;25:681686.
14 Hayashi M, Sugeta A, Takahashi Y, et al: Static and fatigue fracture resistances of pulpless teeth restored with post-cores. Dent Mater 2008;24:1178-1186.

15 Galhano GA, Valandro LF, de Melo RM, et al: Evaluation of the flexural strength of carbon fiber-, quartz fiber-, and glass fiber-based posts. J Endod 2005;31:209-211.

16 Le Bell-Rönnlöf AM, Lassila LV, Kangasniemi I, et al: Load-bearing capacity of human incisor restored with various fiber-reinforced composite posts. Dent Mater 2011;27:e107e115.

17 Cekic-Nagas I, Sukuroglu E, Canay S: Does the surface treatment affect the bond strength of various fibre-post systems to resin-core materials? J Dent 2011;39:171-179.
8 Boschian Pest L, Cavalli G, Bertani P, et al: Adhesive post-endodontic restorations with fiber posts: push-out tests and SEM observations. Dent Mat 2002;18:596-602.

19 Aleisa K, Al-Dwairi ZN, Alghabban R, et al: Effect of luting agents on the tensile bond strength of glass fiber posts: an in vitro study. J Prosthet Dent 2013;110:216-222.

20 Zicari F, van Meerbeek B, Scotti R, et al: Effect of fibre post length and adhesive strategy on fracture resistance of endodontically treated teeth after fatigue loading. J Dent 2012;40: 312-321.

21 Sahinkesen G, Erdemir U, Oktay EA, et al: The effect of post surface silanization and luting agents on the push-out bond strengths of adhesively inserted fiber reinforced posts. Int J Adhes Adhes 2011;31:265-270. 